\title{
Type 2 diabetes is associated with an increased prevalence of respiratory symptoms as compared to the general population
}

\author{
F. De Santi ${ }^{1}$, G. Zoppini ${ }^{1}$, F. Locatelli ${ }^{2}$, E. Finocchio ${ }^{2}$, V. Cappa ${ }^{2}$, M. Dauriz ${ }^{1}$ and G. Verlato ${ }^{2^{*}}$ (D)
}

\begin{abstract}
Background: To estimate the prevalence of respiratory symptoms in individuals with type 2 diabetes, as compared to the general population.

Methods: Between 2007 and 2010 the screening questionnaire of GEIRD (Gene Environment Interactions in Respiratory Diseases) study was administered to two samples of Verona general population, aged respectively 45-64 years and 65-84 years, and to a convenience sample of individuals with type 2 diabetes, consequently recruited at the local Diabetes Centre. Ninety-four and 165 people with type 2 diabetes, aged respectively 45-64 and 65-84 years, were compared with 676 and 591 subjects in the same age range from the general population. The influence of type 2 diabetes on respiratory symptoms was evaluated by logistic regression models, controlling for sex, age (45-54, 55-64, 65-74, 75-84 years), education level, smoking habits and heavy vehicle traffic exposure and adjusting standard errors of ORs for intra-sample correlation.
\end{abstract}

Results: Compared to the general population, dyspnoea limiting walking pace on level ground (grade 2 dyspnoea) was more frequently reported by people with type 2 diabetes, irrespective of age $(p<0.001)$, while self-reported chronic cough/phlegm was more common in those aged $45-64$ years $(p=0.02)$. These results were confirmed by multivariable analysis: compared to their counterparts from the general population, people with type 2 diabetes aged $45-54$ years showed an increased risk of reporting grade 2 dyspnoea ( $\mathrm{OR}=3.92,95 \% \mathrm{Cl} 3.28-4.68)$ or chronic cough/phlegm $(\mathrm{OR}=1.69,1.60-1.78)$. Similar figures held significant at older ages (75-84 years), although partially blunted (dyspnoea: $\mathrm{OR}=1.79,1.68-1.91$; chough/phlegm: $\mathrm{OR}=1.09,1.03-1.16)$. As such, the interaction between age class and type 2 diabetes was significant for both respiratory disorders. The proportion of self-reported dyspnoea among individuals with type 2 diabetes significantly increased across incremental body-mass index (BMI), from 15.4 to $25.4 \%$ and further to $41.3 \%$ respectively in normoweight, overweight and obese patients $(p=0.048)$.

Conclusions: People with type 2 diabetes more frequently reported grade 2 dyspnoea and chronic cough/ phlegm than the general population of the same age, although presenting similar smoking habits. Diabetes appears to anticipate the lung ageing process, recorded in the general population. The increased occurrence of dyspnoea at incremental BMI among individuals with type 2 diabetes may reflect both cardiovascular and respiratory impairment in this high-risk patient population.

Keywords: Dyspnoea, Chronic cough/phlegm, Eczema, Asthma-like symptoms, Type 2 diabetes, Ageing, Obesity, Smoking

\footnotetext{
* Correspondence: giuseppe.verlato@univr.it

${ }^{2}$ Unit of Epidemiology and Medical Statistics, Department of Diagnostic and

Public Health, University of Verona, Strada Le Grazie, 8 -, 37134 Verona, Italy

Full list of author information is available at the end of the article
} 


\section{Background}

Both diabetes and respiratory disorders are highly prevalent in elderly subjects $[1,2]$ and often coexist in the same subjects. Almost one-half of patients with chronic bronchitis or chronic obstructive pulmonary disease (COPD) have coexisting metabolic syndrome [3, 4] and about 20\% have diabetes [5]. COPD has been suggested to be a risk factor for diabetes [6,7], but also the reverse has been reported [8]. As these two conditions both present low-grade chronic inflammation [9], they have been recently enclosed in a common general entity, also referred to as "chronic systemic inflammatory syndrome" [10]. In addition, disturbances of glucose metabolism have been found in asthmatic patients [11].

Metabolic syndrome and diabetes are associated with a modest, albeit statistically significant, impairment of pulmonary function in a restrictive pattern [2, 12-14]; however, it is currently still under debate whether and to what extent the prevalence of respiratory symptoms differs between individuals with and without diabetes. Therefore, the present study aimed at investigating the prevalence of respiratory symptoms in subjects with type 2 diabetes, as compared to the general population.

\section{Methods}

\section{Studied samples}

In the frame of the GEIRD (Gene Environment Interactions in Respiratory Diseases) study [15] two samples aged respectively 45-64 and 65-84 years, each comprising 1000 subjects and with a male to female ratio of one, were randomly selected from the general population of Verona, using local health authority registry. Between 2007 and 2010 both samples were administered the GEIRD screening questionnaire, achieving a response percentage of $70.1 \%(676 / 965)$ and $60.7 \%$ (591/973) respectively (after excluding subjects who had died or moved). Between July 2009 and September 2010 the same questionnaire was given to a convenience sample of outpatients with type 2 diabetes, consequently recruited in the local Diabetes Centre (response percentage $=95.7 \%)$. Ninety-four and 165 outpatients with diabetes, aged respectively 45-64 and 65-84 years, were compared with 676 and 591 subjects in the same age range from the general population.

\section{Assessment of respiratory disorders}

The screening questionnaire used to assess respiratory health was a modified version of the ECRHS (European Community Respiratory Health Survey) questionnaire [16], enquiring about socio-demographic characteristics, education level, smoking habits, outdoor exposure, respiratory symptoms, history of asthma, rhinitis, chronic bronchitis and eczema, and life impairment (GEIRD 2010; available at www.geird.org) [15].
Subjects were classified as having "current asthma" if they reported asthma attacks during the last 12 months or currently taking medicines for asthma, "ever asthma" if they reported the disease during the lifespan. Allergic rhinitis and eczema were defined respectively by a positive answer to the questions "Do you have any nasal allergies including hay fever?" or "Have you ever had atopic dermatitis or eczema, confirmed by a doctor?". Chronic bronchitis was assumed if the subject answered affirmatively to the question "Have you had cough and phlegm on most days for a minimum of three months a year and for at least two successive years?".

Self-reported doctor-diagnosed asthma or COPD were also considered, defined respectively by a positive answer to the questions "Was asthma diagnosed by a doctor?" or "Have you ever been told by a doctor that you have or had chronic bronchitis, chronic obstructive pulmonary disease (COPD) or emphysema?".

Modified Medical Research Council (mMRC) grade2 dyspnoea was assumed when the subject reported to "walk slower than contemporaries on level ground because of breathlessness", or to "stop for breath when walking at own pace".

\section{Assessment of exposures}

With regard to the smoking habits, subjects were classified as follows: 1) current smokers, if they reported to have smoked at least one cigarette per day or one cigar per week for 1 year, and also during the last month; 2) ex-smokers, if they had smoked at least one cigarette per day or one cigar per week for 1 year, but not in the last month; 3) never smokers, otherwise. A previous study conducted in Verona identified a good agreement (Cohen's $\mathrm{k}=0.93$ ) between self-reported smoking behavior and serum cotinine levels in participants to the ECRHS I [17].

Heavy vehicle traffic exposure was assessed by the question "How often do heavy vehicles (e.g. trucks/buses) pass your house?", whose possible answers were "never/ seldom/ frequently/ constantly". In Italian participants to the ECRHS II, a good relation was found between selfreported level of heavy vehicle traffic exposure and NO2 outdoor concentration, measured by passive sampling tubes outside participants' homes [18].

\section{Assessment of body-mass index and glycated haemoglobin}

Information on body-mass index (BMI) and glycated haemoglobin (HbA1c) was available, respectively, in 146 (56.4\%) and 179 (69.1\%) individuals with type 2 diabetes. BMI was calculated by objectively measuring height (with a Harpenden stadiometer) and weight (with a properly calibrated scale), and by dividing weight in kilograms by the square of height in metres. A venous blood 
sample was drawn in the morning after an overnight fast. Haemoglobin A1c was measured by a highperformance liquid chromatography analyzer (Bio-Rad Diamat, Milan, Italy); the upper limit of normal for the laboratory was $5.8 \%$.

Patients were classified according to BMI categories as normoweight (BMI $\left.<25 \mathrm{Kg} / \mathrm{m}^{2}\right)$, overweight $\left(25-29 \mathrm{Kg} / \mathrm{m}^{2}\right)$ or obese $\left(\mathrm{BMI} \geq 30 \mathrm{Kg} / \mathrm{m}^{2}\right)$. Un-satisfactory glycaemic control was considered at $\mathrm{HbA} 1 \mathrm{c} \geq 7 \%$ and patients were classified accordingly in two categories (satisfactory vs. suboptimal glycaemic control).

\section{Statistical analyses}

Significance of differences between individuals with type 2 diabetes and the general population samples of the same age was evaluated by Fisher's exact test for categorical variables, by chi-square test for trend for ordinal variables and by Wilcoxon-Mann-Whitney non-parametric test for continuous variables.

Significant differences in respiratory symptoms, detected in univariable analysis, were verified in multivariable analysis. The latter was accomplished by logistic regression models, where respiratory symptoms, taken one at a time, were the response variable, diabetes the explanatory variable, and sex, age (45-54 (reference), 5564, 65-74, 75-84 years), education level (primary school (reference)/ secondary school/ high school or University), smoking habits (never (reference)/ past/ current smoker) and heavy vehicle traffic exposure (constantly/frequently exposed vs. seldom/never exposed) the potential confounders. Standard errors of ORs were adjusted for intrasample correlation.

In people with type 2 diabetes, statistical significance of the influence of BMI (normoweight/ overweight/ obese) or HbA1c (satisfactory/ sub-optimal) on respiratory symptoms was evaluated by Fisher's exact test, and when the association was significant in univariable analysis, a further evaluation was accomplished by a logistic regression model, controlling for sex, age (65-84 vs. 45-64 years), smoking habits (past/current vs. never smoker).

\section{Results}

The demographic characteristics, education level, smoking habits and traffic exposure of the samples under studies are shown in Table 1. People with type 2 diabetes had a lower proportion of women than the general population in the age range 45-64 years. Individuals with diabetes of all ages had attained a lower education level and were more exposed to heavy vehicle traffic than their coevals from the general population. Smoking habits did not significantly differ between people with type 2 diabetes and the general population, although the former presented a slightly higher proportion of exsmokers.
Individuals with diabetes of all ages more frequently reported dyspnoea limiting walking pace (modified MRC grade 2 dyspnoea) than their coevals $(p<0.001)$ (Table 2$)$. Compared to the general population, self-reported chronic cough/phlegm was more common among individuals with diabetes aged 45-64 years $(p=0.017)$, while self-reported eczema tended to be more common, although not significantly, among those aged 65-84 years $(p=0.087)$.

Significant differences recorded in univariate analysis were verified in multivariable analysis, where a remarkable difference was detected in age-related pattern of respiratory disorders between the general population and people with type 2 diabetes. In the general population, the risk of reporting chronic cough/phlegm (Fig. 1) or mMRC grade 2 dyspnoea (Fig. 2) increased three-fold from 45- 54 years to 75-84 years. Among people with type 2 diabetes the risk of these respiratory disorders was particularly high in the younger age classes, but the increasing trend across incremental age categories was less pronounced. As a consequence, individuals with diabetes presented a greater risk of respiratory disorders than the general population in the younger age classes, while the difference tended to fade with ageing. With respect to the general population, the OR of mMRC grade 2 dyspnoea among individuals with diabetes was nearly four $(3.92,95 \%$ CI $3.28-4.68 ; p<0.001)$ in the age class $45-54$ years, and decreased to $1.79(1.68-1.91 ; p<0.001)$ in the age class $75-84$ years (Fig. 2). Similarly, the ORs of chronic chough/phlegm decreased from 1.69 (1.60$1.78 ; p<0.001)$ to $1.09(1.03-1.16 ; p=0.006)$ across the same age ranges (Fig. 1). As a consequence, the interaction between age class and diabetes was significant for both respiratory disorders.

With regard to the other variables included in the model, constant/frequent exposure to heavy vehicle traffic was associated with a significant increase in the risk of both chronic cough/phlegm $(\mathrm{OR}=2.15,1.85-2.48$; $p<0.001)$ and mMRC grade 2 dyspnoea $(\mathrm{OR}=1.67$, $1.36-2.06 ; p<0.001$ ), with respect to absent/rare exposure. Moreover, chronic cough/phlegm was more frequently reported by past smokers $(\mathrm{OR}=1.47,1.09-1.97$; $p=0.011)$ and current smokers $(\mathrm{OR}=3.09,2.23-4.30$; $p<0.001)$, as compared to never smokers, while mMRC grade 2 dyspnoea was more frequently reported by women $(\mathrm{OR}=2.02,1.14-3.59 ; p=0.016)$ with respect to men.

Most subjects with diabetes were overweight (48\%) or obese $(33 \%)$ and more than a half $(61 \%)$ did not achieve a satisfactory glycemic control, having HbA1c $\geq 7 \%$. Median BMI was $28.0 \mathrm{Kg} / \mathrm{m}^{2}$ (interquartile range 25.532.0) and median HbAlc was 7.25\% (6.4-8.3). Of note, the proportion of self-reported dyspnoea among people with diabetes increased across incremental BMI categories from 15.4 to $25.4 \%$ and further to $41.3 \%$, respectively, 
Table 1 Demographic characteristics, education level and exposure to smoking or heavy vehicle traffic in the study samples

\begin{tabular}{|c|c|c|c|c|c|c|}
\hline & \multicolumn{3}{|l|}{ 45-64 years } & \multicolumn{3}{|l|}{$65-84$ years } \\
\hline & $\begin{array}{l}\text { General population } \\
(n=676)\end{array}$ & $\begin{array}{l}\text { Diabetic patients } \\
(n=94)\end{array}$ & $p$ value & $\begin{array}{l}\text { General population } \\
(n=591)\end{array}$ & $\begin{array}{l}\text { Diabetic patients } \\
(n=165)\end{array}$ & $p$ value \\
\hline Female (\%) & $360(53.3)$ & 37 (39.4) & 0.015 & $261(44.2)$ & $66(40.2)$ & 0.375 \\
\hline Age (mean $\pm S D)$ & $55.3( \pm 5.8)$ & $56.1( \pm 5.8)$ & $z=-1.30, p=0.193$ & $73.3( \pm 5.5)$ & $73.2( \pm 5.5)$ & $z=0.20, p=0.842$ \\
\hline Education level (\%) & & & $\begin{array}{l}z=-4.73 \\
p<0.001\end{array}$ & & & $\begin{array}{l}z=-6.58 \\
p<0.001\end{array}$ \\
\hline Primary school & $86(15.6)$ & 29 (31.5) & & $258(44.2)$ & $119(74.8)$ & \\
\hline Secondary school & $186(33.6)$ & $36(39.1)$ & & $162(27.7)$ & $24(15.1)$ & \\
\hline High school & $192(34.7)$ & $24(26.1)$ & & $120(20.5)$ & $15(9.4)$ & \\
\hline University & $89(16.1)$ & $3(3.3)$ & & $44(7.5)$ & $1(0.6)$ & \\
\hline Smoking habits (\%) & & & 0.418 & & & 0.560 \\
\hline Never-smokers & $278(42.1)$ & $31(34.8)$ & & $330(57.8)$ & 85 (55.6) & \\
\hline Ex-smokers & $228(34.6)$ & 35 (39.3) & & 185 (32.4) & $56(36.6)$ & \\
\hline Current smokers & $154(23.3)$ & $23(25.8)$ & & $56(9.8)$ & $12(7.8)$ & \\
\hline $\begin{array}{l}\text { Heavy vehicle traffic } \\
\text { exposure }\end{array}$ & & & $\begin{array}{l}z=-2.51 \\
p=0.012\end{array}$ & & & $\begin{array}{r}z=-6.43 \\
p<0.001\end{array}$ \\
\hline Never & $121(22.1)$ & $18(20.2)$ & & $144(25.1)$ & $15(9.3)$ & \\
\hline Seldom & $236(43.1)$ & $32(36.0)$ & & 227 (39.6) & $59(36.4)$ & \\
\hline Frequently & $113(20.7)$ & $11(12.4)$ & & $128(22.3)$ & $30(18.5)$ & \\
\hline Constantly & $77(14.1)$ & $28(31.5)$ & & 74 (12.9) & $58(35.8)$ & \\
\hline
\end{tabular}

$P$ values were computed by Fisher's exact test for sex and smoking habits, chi-square test for trend for education and exposure to heavy vehicle traffic and Wilcoxon-Mann-Whitney non-parametric test for age. Significant results are highlighted in bold

in normoweight, overweight and obese outpatients ( $p=0.048)$. When controlling for sex, age, smoking habits by a logistic regression model, the resulting OR of grade 2 dyspnoea was $2.07(0.58-7.38 ; p=0.262)$ in overweight patients with type 2 diabetes and 4.51 (1.2216.70; $p=0.024$ ) in obese patients, with respect to normoweight patients. Glycated haemoglobin was significantly associated with eczema: patients with HbA1c $<7 \%$ more frequently reported eczema than the other patients $(28 \%$ vs. $12 \% ; p=0.013)$, and in the multivariable logistic model they presented an OR of self-reported eczema of $3.2(1.3-8.1 ; p=0.013)$ with respect to patients with $\mathrm{HbA} 1 \mathrm{c} \geq 7 \%$. No other significant association between BMI or HbA1c and respiratory disorders in individuals with type 2 diabetes was detected.

\section{Discussion}

The main results of the present study are:

First, individuals with type 2 diabetes more frequently reported chronic cough and phlegm, and grade 2 dyspnoea

Table 2 Prevalence of respiratory disorders in the study samples

\begin{tabular}{|c|c|c|c|c|c|c|}
\hline & \multicolumn{3}{|l|}{$45-64$ years } & \multicolumn{3}{|l|}{$65-84$ years } \\
\hline & $\begin{array}{l}\text { General population } \\
(n=676)\end{array}$ & $\begin{array}{l}\text { Diabetic patients } \\
(n=94)\end{array}$ & $p$ value & $\begin{array}{l}\text { General population } \\
(n=591)\end{array}$ & $\begin{array}{l}\text { Diabetic patients } \\
(n=165)\end{array}$ & $p$ value \\
\hline Ever asthma (\%) & $58(8.8)$ & $9(9.7)$ & 0.702 & $42(7.5)$ & $10(6.2)$ & 0.730 \\
\hline Current asthma (\%) & $39(5.8)$ & $6(6.5)$ & 0.814 & $25(4.4)$ & $8(4.9)$ & 0.830 \\
\hline Diagnosed asthma (\%) & $43(6.6)$ & $6(6.7)$ & 1.00 & $27(4.9)$ & $5(3.1)$ & 0.513 \\
\hline Allergic rhinitis (\%) & $125(18.7)$ & $15(16.5)$ & 0.668 & $75(13)$ & $24(15.1)$ & 0.513 \\
\hline Eczema (\%) & 89 (13.6) & $14(15.6)$ & 0.626 & $70(12.8)$ & $28(18.3)$ & 0.087 \\
\hline Chronic cough/phlegm (\%) & $108(16.7)$ & $24(27.6)$ & 0.017 & $134(24.6)$ & $41(27.9)$ & 0.454 \\
\hline Diagnosed COPD (\%) & $41(6.2)$ & $7(7.9)$ & 0.496 & $78(14.0)$ & $18(11.8)$ & 0.593 \\
\hline mMCR grade2 dyspnoea (\%) & $52(7.9)$ & $20(23)$ & $<0.001$ & 77 (13.7) & $47(30.9)$ & $<0.001$ \\
\hline
\end{tabular}

$P$ values were computed by Fisher's exact test. Significant results are highlighted in bold 


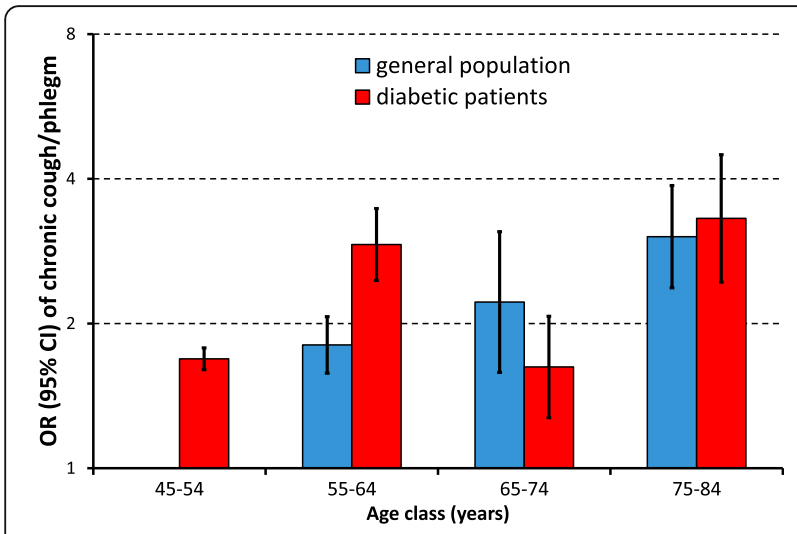

Fig. 1 Odds ratios (ORs) of reporting chronic cough/phlegm in the general population (blue columns) and in individuals with type 2 diabetes (red columns) as a function of age class. Columns are ORs, bars are $95 \%$ confidence intervals. ORs were computed by a logistic regression model, controlling for sex, age, education level, smoking habits and exposure to heavy vehicle traffic

as compared to the general population of the same age, although presenting similar smoking habits. These differences tended to decrease at older ages, thus suggesting that diabetes induces an accelerating ageing of the lung.

Second, grade 2 dyspnoea was most often reported by obese outpatients with type 2 diabetes.

Third, the prevalence of asthma or allergic rhinitis was not significantly associated with diabetes. Eczema tended to be more prevalent in individuals with type 2 diabetes within the age range 65-84 years, although the association was not statistically significant.

The most remarkable finding of the present study was a three-to-four fold increase in dyspnoea observed in individuals with type 2 diabetes with respect to the general

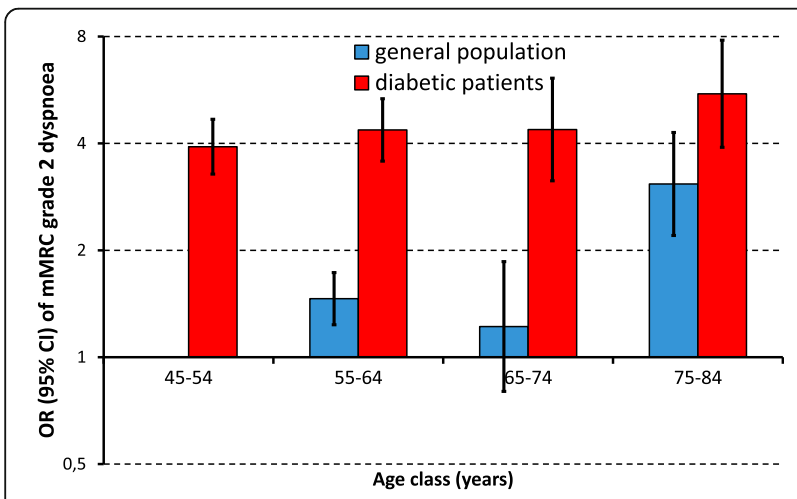

Fig. 2 Odds ratios (ORs) of reporting mMRC grade 2 dyspnoea in the general population (blue columns) and in individuals with type 2 diabetes (red columns) as a function of age class. Columns are ORs, bars are $95 \%$ confidence intervals. ORs were computed by a logistic regression model, controlling for sex, age, education level, smoking habits and exposure to heavy vehicle traffic population. Accordingly, available literature supports the notion that the lung is a target organ for diabetic injury [19] and that type 2 diabetes is associated with reduced lung volumes and airflow limitation [20]. Usually, a pattern of modest lung restriction and reduced diffusion capacity has been described in individuals with type 2 diabetes [13, 14, 21, 22]. However, some studies have also linked obstructive diseases, in particular COPD, to metabolic syndrome or impaired glucose tolerance [10, 23].

In the present study, the prevalence of diagnosed COPD did not differ between individuals with type 2 diabetes and coevals from the general population. However, chronic cough/phlegm, which was once considered the first stage of the disease (GOLD stage 0) [24], was more commonly reported by people with diabetes.

Although dyspnoea is the distinctive hallmark of most respiratory diseases, obesity or impairment of the cardiovascular system may be responsible for the increased prevalence of dyspnoea among individuals with type 2 diabetes. However, impairment of both cardiovascular and respiratory systems may frequently coexist in the same subject. The recent ECLIPSE epidemiological study found that diabetes was associated with higher MRC dyspnoea scores and reduced 6-min walk distance and that comorbidities of heart disease and diabetes correlated with increased systemic inflammation [25].

Individuals with type 2 diabetes self-reported a higher level of exposure to heavy vehicle traffic than the general population, and this difference could partly explain the higher prevalence of dyspnoea and chronic cough/ phlegm among people with type 2 diabetes. However, the association between type 2 diabetes and respiratory disorders persisted even after controlling for traffic exposure in a multivariable model.

In the present study an increased prevalence of eczema was observed among older individuals with type 2 diabetes. However, although an association between diabetes and eczema was expected on the basis of current literature, this figure did not reach significance, possibly due to limited statistical power. Indeed, topical steroids are often used for long-term control of eczema despite contraindications, and this could not only worsen eczema, but also elicit insulin resistance. An altered glucose metabolism occurs in nearly half of glucocorticoid-treated patients, even after treatment reduction or withdrawal [26]. Moreover, a larger amount of steroid could be absorbed during topic treatment in elderly individuals, due to reduced skin thickness [27]. Alternately, insulin resistance status could induce eczema, by decreasing the expression of $\Delta-6$ desaturase [28], an hepatic enzyme involved in the synthesis of gamma-linolenic acid, whose levels are reduced in atopic eczema [29].

Asthma-like symptoms have been reported to be more frequent in adults with metabolic syndrome [30] or with 
insulin resistance, a basic alteration of type 2 diabetes [31]. Other authors have argued that insulin itself may increase the contractility of airway smooth muscle cells, thus contributing to bronchial hyper-responsiveness [21]. However, these findings were not supported by the present research, as the prevalence of diagnosed or selfreported asthma was similar in both individuals with type 2 diabetes and in the general population.

\section{Pathophysiologic mechanisms}

Hyperglycemia could trigger inflammatory response, thus leading to structural modification of pulmonary tissue and impaired lung function [9]. Moreover, lung function volumes have been shown to be inversely associated with insulin resistance [31].

On the other hand, it could be also hypothesized that diabetes can worsen or even accelerate the derangement of respiratory function by inducing structural alterations $[9,32]$. In fact, the pulmonary alveolar-capillary network is a large microvascular unit that may also be affected by diabetic microangiopathy [33]. Human autopsy studies in subjects with diabetes have observed cell proliferation with hypertrophy of interstitial matrix, increased thickness of the bronchial, alveolar and capillary basement membranes and an accompanying collapse of the alveolar space [34]. In this regard, a recent study reported a significant reduction of carbon monoxide diffusing capacity in individuals with diabetes, as compared to their counterparts without diabetes [35]. This structural alteration may also be related to the increased risk of individuals with diabetes to be hospitalized for pneumonia $[35,36]$.

\section{Strengths and limitations}

A strength of this study was the use of a standardized internationally-validated questionnaire to assess respiratory health. In addition, when assessing the impact of diabetes on respiratory symptoms, samples from the general population of the same age were considered as reference.

Smoking is the main risk factor for respiratory diseases in the Western world, being responsible for up to $80-90 \%$ of COPD cases [37], but it also enhances the risk of developing type 2 diabetes [38-40]. Hence, smoking status may act as a confounder of the relation between diabetes and respiratory health. However, in the present study smoking habits were not significantly different between individuals with type 2 diabetes and their counterparts from the general population. Moreover, multivariable analysis was adjusted for self-reported smoking history, as well as for heavy vehicle traffic exposure.

However, some limitations should also be acknowledged. First, information on respiratory health was collected by a self-administered questionnaire without direct assessment of respiratory function. Second, response percentage was higher among individuals with type 2 diabetes $(95.7 \%)$ than in the general population samples (70.1 and 60.7\%, respectively, in people aged 45-64 and 65-84 years). As people with respiratory disorders tend to be early responders to self-administered questionnaires [41], a reduction in response percentage may have led to overestimate the prevalence of respiratory symptoms in the general population, thus partly masking the difference between individuals with type 2 diabetes and the general population. Third, the prevalence of type 2 diabetes can be expected to be around $10 \%$ in the general Italian population aged 45-84 years $[1,42]$. However, individuals with diabetes could not be excluded from general population samples, as the GEIRD screening questionnaire did not enquire about this disease. This probably could have also led to underestimate differences in respiratory disorders between subjects with diabetes and the general population. Finally, the cross-sectional design of the present study does allow to detect associations, such as between respiratory disorders and type 2 diabetes, but not to infer the causal relation involved.

\section{Conclusions}

In conclusion, our data confirmed the evidence of an increased prevalence of respiratory symptoms (dyspnoea, chronic cough/phlegm) in individuals with type 2 diabetes, when compared to the general population of the same age. This difference was larger in the age range 45-64 years than at older ages, thus suggesting that diabetes may anticipate the lung ageing process. Therefore, our results may be relevant to the practicing physicians as they highlight the potential clinical utility of an early screening for respiratory diseases in individuals with type 2 diabetes. When deemed necessary, the prompt initiation of specific treatments for respiratory diseases would be advisable by comprehensively accounting for the accompanying multimorbidities and modifiable risk factors.

\section{Abbreviations \\ BMI: Body Mass Index; COPD: Chronic Obstructive Pulmonary Disease; ECRHS: European Community Respiratory Health Survey; GEIRD: Gene Environment Interactions in Respiratory Diseases; HbA1c: Glycated Haemoglobin; mMRC: Modified Medical Research Council grade 2 dyspnoea}

\footnotetext{
Acknowledgements

The authors would like to thank Roberta Vesentini for the support provided in the submission of the study documentation for the ethics committee approval.

Funding

The GEIRD project was funded by the Cariverona Foundation (Verona, Italy) and by the Italian Ministry of Education, Universities and Research (MIUR) The funding sources had no involvement in the study design, collection, analysis and interpretation of data, writing of the report or decision to submit the paper for publication.
} 


\section{Availability of data and materials}

The datasets generated and/or analysed during the current study are available from the corresponding author on reasonable request.

\section{Authors' contributions}

GZ and GV devised the present study. GZ, FDS and MD distributed and collected the questionnaires to the individuals with type 2 diabetes and collected information on BMI and HbA1c. GV, FL and VC contributed to data collection from the general population in the frame of the GEIRD study. FL, EF and VC performed the statistical analysis. FDS, GZ and GV drafted the preliminary manuscript. All authors read, improved and approved the final manuscript.

\section{Ethics approval and consent to participate}

The present study was approved by "Comitato Etico per la Sperimentazione Clinica delle Province di Verona e Rovigo", Dipartimento Direzione Medica Ospedaliera, Azienda Ospedaliera Universitaria Integrata Verona (approval prot. N. 42,768). All participants gave informed consent.

\section{Consent for publication}

Not applicable.

\section{Competing interests}

G. Verlato is Section Editor of BMC Pulmonary Medicine, for the Section Epidemiology and Public Health. G. Verlato received financial support from BioMed Central to participate in the 2014 and 2015 Congresses of the European Respiratory Society. G. Verlato is handling a grant for the clinical stage of the GEIRD study, given to the late Roberto de Marco by Chiesi Farmaceutici S.p.A. All remaining authors declare that they have no competing interests.

\section{Publisher's Note}

Springer Nature remains neutral with regard to jurisdictional claims in published maps and institutional affiliations.

\section{Author details}

'Division of Endocrinology, Diabetes and Metabolism, Department of Medicine, University of Verona, Verona, Italy. ${ }^{2}$ Unit of Epidemiology and Medical Statistics, Department of Diagnostic and Public Health, University of Verona, Strada Le Grazie, 8 -, 37134 Verona, Italy.

Received: 28 November 2016 Accepted: 9 July 2017

Published online: 17 July 2017

\section{References}

1. Muggeo M, Verlato G, Bonora E, Bressan F, Girotto S, Corbellini M, Gemma ML, Moghetti P, Zenere M, Cacciatori V, Zoppini G, de Marco R. The Verona diabetes study: a population-based survey on known diabetes mellitus prevalence and 5-year all-cause mortality. Diabetologia. 1995;38:318-25.

2. Methvin JN, Mannino DM, Casey BR. COPD prevalence in Southeastern Kentucky. Chest. 2009;135:102-7.

3. Marquis K, Maltais F, Duguay V, Bezeau AM, LeBlanc P, Jobin J, Poirier P. The metabolic syndrome in patients with chronic obstructive pulmonary disease. J Cardpulm Rehabil. 2005;25:226-32.

4. Watz H, Waschki B, Kirsten A, Müller KC, Kretschmar G, Meyer T, Holz O, Magnussen $\mathrm{H}$. The metabolic syndrome in patients with chronic bronchitis and COPD: frequency and associated consequences for systemic inflammation and physical inactivity. Chest. 2009;36:1039-46.

5. Cazzola M, Bettoncelli G, Sessa E, Cricelli C, Biscione G. Prevalence of comorbidities in patients with chronic obstructive pulmonary disease. Respiration. 2010;80:112-9.

6. Rana JS, Mittleman MA, Sheikh J, Hu FB, Manson JE, Colditz GA, Speizer FE, Barr RG, Camargo CA Jr. Chronic obstructive pulmonary disease, asthma, and risk of type 2 diabetes in women. Diabetes Care. 2004;27(10):2478-84.

7. Lee CT, Mao IC, Lin CH, Lin SH, Hsieh MC. Chronic obstructive pulmonary disease: a risk factor for type 2 diabetes: a nationwide population- based study. Eur J Clin Investig. 2013;43:1113-9.

8. Ehrlich SF, Quesenberry CP Jr, Van Den Eeden SK, Shan J, Ferrara A. Patients diagnosed with diabetes are at increased risk for asthma, chronic obstructive pulmonary disease, pulmonary fibrosis, and pneumonia but not lung cancer. Diabetes Care. 2010;33:55-60.
9. Gläser S, Krüger S, Merkel M, Bramlage P, Herth FJF. Chronic obstructive pulmonary disease and diabetes mellitus: a systematic review of the literature. Respiration. 2015;89:253-64.

10. Fabbri LM, Rabe KF. From COPD to chronic systemic inflammatory syndrome ? Lancet. 2007;370:797-9.

11. Gulcan E, Bulut I, Toker A, Gulcan A. Evaluation of glucose tolerance status in patients with asthma bronchiale. J Asthma. 2009;46:207-9.

12. Fimognari FL, Pasqualetti P, Moro L, Franco A, Piccirillo G, Pastorelli R, Rossini PM, Antonelli-Incalzi R. The association between metabolic syndrome and restrictive ventilatory dysfunction in older persons. J Gerontol A Biol Sci Med Sci. 2007;62:760-5.

13. Tiengo A, Fadini GP, Avogaro A. The metabolic syndrome, diabetes and lung dysfunction. Diabetes Metab. 2008:34:447-54.

14. van den Borst B, Gosker HR, Zeegers MP, Schols AM. Pulmonary function in diabetes: a meta-analysis. Chest. 2010;138:393-406.

15. Verlato G, Accordini S, Nguyen G, Marchetti P, Cazzoletti L, Ferrari M, Antonicelli L, Attena F, Bellisario V, Bono R, Briziarelli L, Casali L, Corsico AG, Fois A, Panico MG, Piccioni P, Pirina P, Villani S, Nicolini G, de Marco R. Socioeconomic inequalities in smoking habits are still increasing in Italy. BMC Public Health. 2014;14:879.

16. de Marco R, Zanolin ME, Accordini S, Signorelli D, Marinoni A, Bugiani M, Lo Cascio V, Woods R, Burney P. A new questionnaire for the repeat of the first stage of the European Community respiratory health survey (ECRHS): a pilot study. Eur Respir J. 1999;14:1044-8.

17. Olivieri M, Poli A, Zuccaro P, Ferrari M, Lampronti G, de Marco R, Lo Cascio V, Pacifici R. Tobacco smoke exposure and serum cotinine in a random sample of adults living in Verona, Italy. Arch Environ Health. 2002;57:355-9.

18. Rava M, Verlato G, Bono R, Ponzio M, Sartori S, Blengio G, Kuenzli N, Heinrich J, Götschi T, de Marco R. A predictive model for the home outdoor exposure to nitrogen dioxide. Sci Total Environ. 2007;384:163-70.

19. Goldman MD. Lung dysfunction in diabetes. Diabetes Care. 2003;26(6):1915-8.

20. Davis WA, Knuiman M, Kendall P, Grange V, Davis TM, Fremantle Diabetes Study. Glycemic exposure is associated with reduced pulmonary function in type 2 diabetes: the Fremantle diabetes study. Diabetes Care. 2004;27(3):752-7.

21. Gosens R, Nelemans SA, Hiemstra M, Grootte Bromhaar MM, Meurs H, Zaagsma J. Insulin induces a hypercontractile airway smooth muscle phenotype. Eur J Pharmacol. 2003;481:125-31.

22. Yeh HC, Punjabi NM, Wang NY, Pankow JS, Duncan BB, Cox CE, Selvin E, Brancati FL. Cross-sectional and prospective study of lung function in adults with type 2 diabetes: the atherosclerosis risk in communities (ARIC) study. Diabetes Care. 2008;31:741-6.

23. McKeever TM, Weston PJ, Hubbard R, Fogarty A. Lung function and glucose metabolism: an analysis of data from the third National Health and nutrition examination survey. Am J Epidemiol. 2005;101:546-56.

24. de Marco R, Accordini S, Cerveri I, Corsico A, Sunyer J, Neukirch F, Kunzli N, Leynaert B, Janson C, Gislason T, Vermeire P, Svanes C, Anto JM, Burney P. An international survey of chronic obstructive pulmonary disease in young adults according to GOLD stages. Thorax. 2004;59(2):120-5.

25. Miller J, Edwards LD, Agustí A, Bakke P, Calverley PM, Celli B, Coxson HO, Crim C, Lomas DA, Miller BE, Rennard S, Silverman EK, Tal-Singer R, Vestbo J, Wouters E, Yates JC, MacNee W. Evaluation of COPD longitudinally to identify predictive surrogate endpoints (ECLIPSE) investigators. Comorbidity, systemic inflammation and outcomes in the ECLIPSE cohort. Respir Med. 2013;107(9):1376-84

26. Mever G, Badenhoop K. Glucocorticoid-induced insulin resistance and diabetes mellitus. Receptor-, postreceptor mechanisms, local cortisol action, and new aspects of antidiabetic therapy. Med Klin (Munich). 2003;98(5):266-70.

27. Wong VK, Della Croce C, Schonfeld S, Mastrangelo AM, Lebwohl M. Use and abuse of topical corticosteroids in infections of the skin and related structures. J Drugs Dermatol. 2003;2(3):268-76.

28. Rimoldi OJ, Finarelli GS, Brenner RR. Effects of diabetes and insulin on hepatic delta6 desaturase gene expression. Biochem Biophys Res Commun. 2001;283(2):323-6.

29. Horrobin DF. Essential fatty acid metabolism and its modification in atopic eczema. Am J Clin Nutr. 2000;71(1 Suppl):367S-72S.

30. Lee EJ, In KH, Ha ES, Lee K, Hur GY, Kang EH, Jung KH, Lee SY, Kim JH, Shin C, Shim JJ, Kang KH, Yoo SH. Asthma-like symptoms are increased in the metabolic syndrome. J Asthma. 2009:46:339-42.

31. Thuesen BH, Husemoen LL, Hersoug LG, Pisinger C, Linneberg A. Insulin resistance as a predictor of incident asthma-like symptoms in adults. Clin Exp Allergy. 2009;39:700-7. 
32. Hickson DA, Burchfiel CM, Liu J, Petrini MF, Harrison K, White WB, Sarpong DF. Diabetes, impaired glucose tolerance, and metabolic biomarkers in individuals with normal glucose tolerance are inversely associated with lung function: the Jackson heart study. Lung. 2011:189(4):311-21.

33. Chance WW, Rhee C, Yilmaz C, Dane DM, Pruneda ML, Raskin P, Hsia CC. Diminished alveolar microvascular reserves in type 2 diabetes reflect systemic microangiopathy. Diabetes Care. 2008;31:1596-601.

34. Weynand B, Jonckheere A, Frans A, Rahier J. Diabetes mellitus induces a thickening of the pulmonary basal lamina. Respiration. 1999;66:14-9.

35. Klein OL, Smith LJ, Tipping M, Peng J, Williams MV. Reduced diffusion lung capacity in patients with type 2 diabetes mellitus predicts hospitalization for pneumonia. Diabetes Res Clin Pract. 2011;92:e12-5.

36. Kornum JB, Thomsen RW, Riis A, Lervang HH, Schønheyder HC, Sørensen HT. Diabetes, glycemic control, and risk of hospitalization with pneumonia: a population-based case-control study. Diabetes Care. 2008:31:1541-5.

37. Diaz-Guzman E, Mannino DM. Epidemiology and prevalence of chronic obstructive pulmonary disease. Clin Chest Med. 2014;35(1):7-16

38. Pan A, Wang Y, Talaei M, Hu FB, Wu T. Relation of active, passive, and quitting smoking with incident type 2 diabetes: a systematic review and meta-analysis. Lancet Diabetes Endocrinol. 2015;3(12):958-67.

39. Sattar N, Sorensen T, Taylor AE, Morris R, Munafò MR. Smoking and diabetes risk: building a causal case with clinical implications. Lancet Diabetes Endocrinol. 2015;3(12):918-20.

40. The health consequences of smoking - 50 years of progress: a report of the Surgeon General. - Atlanta, GA.: U.S. Department of Health and Human Services, Centers for Disease Control and Prevention, National Center for Chronic Disease Prevention and Health Promotion, Office on Smoking and Health. 2014.

41. Verlato G, Melotti R, Olivieri M, Corsico A, Bugiani M, Accordini S, Villani S, Migliore E, Marinoni A, Pirina P, Carrozzi L, Bortolami O, Rava M, de Marco R. For the ISAYA study group. Asthmatics and ex-smokers respond early, heavy smokers respond late to mailed surveys in Italy. Resp Med. 2010;104(2):172-9.

42. Bianchi C, Rossi E, Miccoli R. Epidemiologia del diabete. In: Bonora E, Sesti G, editors. II diabete in Italia. Bologna (Italy): Bononia University Press; 2016. p. 13-9.

\section{Submit your next manuscript to BioMed Central and we will help you at every step:}

- We accept pre-submission inquiries

- Our selector tool helps you to find the most relevant journal

- We provide round the clock customer support

- Convenient online submission

- Thorough peer review

- Inclusion in PubMed and all major indexing services

- Maximum visibility for your research

Submit your manuscript at www.biomedcentral.com/submit

) Biomed Central 